\title{
The Powers and Perils of PCR in the Search for the Natural Reservoirs of Coccidioides Species
}

\author{
Zhirong Li $\cdot$ Vishnu Chaturvedi
}

Published online: 2 May 2017

(C) Springer Science+Business Media Dordrecht 2017

The soil-dwelling fungus Coccidioides is the causative agents of coccidioidomycosis, also known as San Joaquin Valley Fever or Valley Fever [1, 2]. Coccidioides is transmitted to humans and other animals via the inhalation of airborne spores released from the natural foci of the pathogen [3]. More than half of the individuals exhibit no disease symptoms after the inhalation of the fungal spores [4]. The remaining exposed individuals most commonly develop a flu-like illness, which might progress to chronical lung infection with further dissemination affecting many organ systems [4].

Coccidioides immitis and $C$. posadasii are two distinct species distinguished by multilocus sequencing typing (MLST) and other genetic analyses [2, 5, 6]. Coccidioides posadasii represents the entire nonCalifornia population of the pathogen. Serological assays commonly used for the diagnosis of coccidioidomycosis do not distinguish between $C$. immitis and $C$. posadasii infections [7, 8]. Real-time polymerase chain reaction (PCR) assays are available that

\section{Z. Li}

Howard Hughes Medical Institute, University of

California Berkeley, Berkeley, CA, USA

V. Chaturvedi $(\square)$

California Institute for Medical Research, San Jose, CA,

USA

e-mail: eic@mycopathologia.net differentiate $C$. immitis from $C$. posadasii among clinical isolates $[9,10]$. It is not known whether coccidioidomycosis caused by $C$. immitis or $C$. posadasii differs in clinical severity or outcome.

Coccidioides species are endemic in the desert regions of the southwestern USA, northern Mexico, and sporadic areas in Central and South America. In the soil, Coccidioides species are believed to produce mitospores (arthroconidia) that separate from the parent mycelium and are of sufficiently small size to infect mammalian lung [11]. It is hypothesized that small mammals in the desert likely play a crucial role in the life cycle of the fungus [12-14]. The current understanding of the geographic distribution of $\mathrm{Coc}$ cidioides spp. is inferred indirectly from the results of skin testing conducted in the 1950s [15]. The knowledge about the natural reservoirs of Coccidioides spp. remains incomplete despite the fact that such knowledge is crucial in order to prevent human exposure. The disease burden has increased in the USA at an alarming rate [16]. The reported increase in the annual incidence in California in the last decade has reached 14 persons per 100,000 populations in 2011 [17].

Soil analysis for the recovery of Coccidioides is crucial to identify its natural reservoirs. However, the isolations from soil have been few and far between. $C$. immitis was first isolated from soil samples collected from a disturbed site in the San Joaquin River Valley (California, USA) by Stewart \& Meyer in 1932 [1]. In 1942, Emmons developed an animal passage technique 
for the fungal recovery from soil; this involved the inoculation of small rodents with concentrated spores and subsequent organ cultures [12]. The merits of this procedure were high success rate and the detection of the parasitic spherule form in the animal tissues, which allowed for the definitive identification of the fungus. However, the animal passage has fallen out of favor due to cost, labor, and less permissive environment for vertebrate animal testing. The direct isolation of $C$. immitis from soil samples was improved using various selection media containing antibacterial and antifungal antibiotics [18-20]. These approaches also benefited from studies that showed that $C$. immitis has a selective advantage over other fungal competitors in increased salinity and seasonal high-temperature conditions $[21,22]$. More recently, the double-pour procedure developed by Omieczynsk and Swatek [20] was found superior to other methods because many of the soil saprobic fungi, which are fast growing, are trapped deep in the medium, and therefore allow good growth of Coccidioides spp. The double-pour procedure remains a low-cost alternative with easy scale-up for processing of large number of soil samples for the isolation of $C$. immitis.

Coccidioidomycosis endemic areas continue to expand in the USA and now include Missouri, Utah, and Washington [23-26]. The recent investigations in the Washington state were notable in that the genotype of environmental isolate was correlated with the clinical isolate from Washington using whole genome sequencing (WGS) [24, 26]. This correlation established that the infection was acquired locally. It was a significant finding as Coccidioides present in soil outside of its known range caused local outbreak. The study also highlighted the benefits of environmental sampling concomitant with epidemiological investigations to find out about the point source of exposure.

A study by Colson et al. [27] in this issue of the journal provides a correlation between environment changes due to large-scale land development and the increased incidence of coccidioidomycosis in California. The investigators collected 42 soil samples from six sites destined for solar panel construction in the Antelope Valley of California and used a culture-free, PCR-based approach to test the presence of Coccidioides spp. C. immitis was found in 17 soil samples from four of the six sites. A multiple regression analysis of the number of coccidioidomycosis incidence and environmental parameters was performed.
The study found that large-scale soil disturbances due to renewable energy construction projects, agricultural management practices, and dust emission correlate with the increased incidence of coccidioidomycosis. The authors recommended soil analyses for Coccidioides spp. and implementation of long-term dust mitigation plans in future Environmental Impact Reports (EIR). The study by Colson et al. has several merits including the correlations between epidemiological and laboratory data, the use of high-throughput DNA analysis methods and a remedial plan that could be correlated for efficacy with a laboratory test. The limitations of the study include the use of PCR-based assays for the environmental survey, which could be sensitive to primer selection and hybridization bias, cross-reaction with unidentified species from the mixed community, short read lengths, and low resolution of phylogenetic analysis.

The study by Colson et al. [27] expands recent investigations on the molecular identification of $\mathrm{Coc}$ cidioides in environmental samples with an optimized multiplex PCR method in Bakersfield, California [28], a semi-nested PCR using specific primer in Brazil [29], a nested PCR followed by a diagnostic PCR designed to amplify the internal transcribed spacer (ITS) 2 region in Baja California [30], and an endpoint-nested PCR followed by ITS1 and ITS2 amplification in Dinosaur National Monument, Utah [31]. Thus, there is a volume of rigorous laboratory data that confirm the occurrence of Coccidioides DNA in various locations in the endemic zones. However, we do not know whether the DNA-positive samples harbor live Coccidioides spores and could act as point source of future exposures. Thus, additional studies might be needed to correlate the molecular detection of Coccidioides DNA with the recovery of the fungal isolates in culture from the same environmental samples. Notably, Litvintseva et al. were successful in using PCR screens with the isolation in culture in their comprehensive investigations of human cases [26]. The investigator collected five soil samples in 2010 and fifteen soil samples in 2014 from a dirt track at a public park used for ATV riding in Washington. While all five soil samples collected in 2010 were positive by both "CocciDx" PCR assay and fungal culture, eleven of fifteen soil samples positive by the PCR assay yielded a single positive culture [26]. These limited data suggested that far more samples are likely to be positive for DNA without yielding Coccidioides in culture. 
Understanding the ecology and distribution of Coccidioides is a key to devising preventive strategies against the increased disease burden of coccidioidomycosis. In a recent study, Teixeira and Barker hypothesized the existence of two subpopulations of C. immitis in central and southern California and three subpopulations of C. Posadasii in Arizona, Mexico, and Texas/South America by analyzing 495 clinical and environmental isolates [32]. We believe that the availability of more environmental isolates across large spatial scales will be crucial for future WGS studies. Such genome-wide characterizations of clinical and environmental isolates of Coccidioides species will likely reveal unique ecological niche, pathogen populations, and virulence elements. The knowledge gain will promote better diagnostic and therapeutic approaches informed by the unique genetic makeup of the target strains.

Acknowledgement We thank Dr. John Taylor for critical comments on the manuscript.

\section{References}

1. Stewart RA, Meyer KF. Isolation of Coccidioides immitis (Stiles) from the soil. Proc Soc Exp Biol Med. 1932;29:937-8.

2. Fisher MC, Koenig GL, White TJ, Taylor JW. Molecular and phenotypic description of Coccidioides posadasii sp. nov., previously recognized as the non-California population of Coccidioides immitis. Mycologia. 2002;94(1):73-84.

3. Lewis ER, Bowers JR, Barker BM. Dust devil: the life and times of the fungus that causes valley Fever. PLoS Pathog. 2015;11(5):e1004762.

4. O'Toole M-KMT. Coccidioidomycosis. In: 7th ed. MillerKeane encyclopedia and dictionary of medicine, nursing and allied health, Saunders. 2003.

5. Bowman BH, Taylor JW, White TJ. Molecular evolution of the fungi: human pathogens. Mol Biol Evol. 1992;9(5): 893-904.

6. Neafsey DE, Barker BM, Sharpton TJ, Stajich JE, Park DJ, Whiston E, et al. Population genomic sequencing of Coccidioides fungi reveals recent hybridization and transposon control. Genome Res. 2010;20(7):938-46.

7. Ampel NM. The diagnosis of coccidioidomycosis. F1000 Med Rep. 2010;2:2. doi:10.3410/M2-2.

8. Nguyen C, Barker BM, Hoover S, Nix DE, Ampel NM, Frelinger JA, et al. Recent advances in our understanding of the environmental, epidemiological, immunological, and clinical dimensions of coccidioidomycosis. Clin Microbiol Rev. 2013;26(3):505-25.

9. Umeyama T, Sano A, Kamei K, Niimi M, Nishimura K, Uehara Y. Novel approach to designing primers for identification and distinction of the human pathogenic fungi
Coccidioides immitis and Coccidioides posadasii by PCR amplification. J Clin Microbiol. 2006;44(5):1859-62.

10. Sheff KW, York ER, Driebe EM, Barker BM, Rounsley SD, Waddell VG, et al. Development of a rapid, cost-effective TaqMan real-time PCR assay for identification and differentiation of Coccidioides immitis and Coccidioides posadasii. Med Mycol. 2010;48(3):466-9.

11. Dixon DM. Coccidioides immitis as a select agent of bioterrorism. J Appl Microbiol. 2001;91(4):602-5.

12. Emmons CW. Isolation of Coccidioides from soil and rodents (1896-1970). Public Health Rep. 1942;57(4):109-11.

13. Del Rocio Reyes-Montes M, Perez-Huitron MA, OcanaMonroy JL, Frias-De-Leon MG, Martinez-Herrera E, Arenas $\mathrm{R}$, et al. The habitat of Coccidioides spp. and the role of animals as reservoirs and disseminators in nature. BMC Infect Dis. 2016;16(1):550.

14. Barker BM, Tabor JA, Shubitz LF, Perrill R, Orbach MJ. Detection and phylogenetic analysis of Coccidioides posadasii in Arizona soil samples. Fungal Ecol. 2012;5(2):16376.

15. Edwards PQ, Palmer CE. Prevalence of sensitivity to coccidioidin, with special reference to specific and nonspecific reactions to coccidioidin and to histoplasmin. Chest. 1957;31(1): 35-60.

16. CDC. Increase in reported coccidioidomycosis-United States, 1998-2011. Morb Mortal Wkly Rep. 2013;62(12): 217-21.

17. Thompson GR III, Stevens DA, Clemons KV, Fierer J, Johnson RH, Sykes J, et al. Call for a California Coccidioidomycosis consortium to face the top ten challenges posed by a recalcitrant regional disease. Mycopathologia. 2015;179(1):1-9.

18. Georg LK, Ajello L, Gordon MA. A selective medium for the isolation of Coccidioides immitis. Science. 1951; 114(2963):387.

19. Egeberg RO, Ely AF. Coccidioides immitis in the soil of the Southern San Joaquin Valley. Am J Med Sci. 1956; 231(2):151-4.

20. Omieczynski BS, Swatek FE. The comparison of two methods for the direct isolation of Coccidioides immitis from soil using three different media. In: Ajello L, Edl Coccidioidomycosis, proceedings of the second Coccidioidomycosis symposium Tucson. Arizona: University of Arizona Press Science; pp. 265-72.

21. Egeberg RO, Elconin AE, Egeberg MC. Effect of salinity and temperature on Coccidioides immitis and three antagonistic soil saprophytes. J Bacteriol. 1964;88(2):473-6.

22. Elconin AF, Egeberg RO, Egeberg MC. Significance of soil salinity on the ecology of Coccidioides immitis. J Bacteriol. 1964;87(3):500-3.

23. Turabelidze G, Aggu-Sher RK, Jahanpour E, Hinkle CJ. Coccidioidomycosis in a state where it is not known to be endemic-Missouri, 2004-2013. Morb Mortal Wkly Rep. 2014;64(23):636-9.

24. Marsden-Haug N, Hill H, Litvintseva AP, Engelthaler DM, Driebe EM, Roe CC, et al. Coccidioides immitis identified in soil outside of its known range-Washington, 2013. Morb Mortal Wkly Rep. 2014;63(20):450.

25. Lyle RP, Stacie LM, Christine B, Rana AH, Mark DL, David WW, et al. Coccidioidomycosis among workers at an 
archeological site, Northeastern Utah. Emerg Infect Dis J. 2004;10(4):637.

26. Litvintseva AP, Marsden-Haug N, Hurst S, Hill H, Gade L, Driebe EM, et al. Valley fever: finding new places for an old disease: Coccidioides immitis found in Washington state soil associated with recent human infection. Clin Infect Dis. 2015;60(1):e1-3.

27. Colson AJ, Vredenburgh L, Guevara RE, Rangel NP, Kloock CT, Lauer A. Large-scale land development, fugitive dust, and increased coccidioidomycosis incidence in the antelope valley of California, 1999-2014. Mycopathologia. 2017:1-20. doi:10.1007/s11046-016-0105-5.

28. Lauer A, Baal JDH, Baal JCH, Verma M, Chen JM. Detection of Coccidioides immitis in Kern County, California, by multiplex PCR. Mycologia. 2012;104(1):62-9.

29. de Macêdo RCL, Rosado AS, da Mota FF, Cavalcante MAS, Eulálio KD, Filho AD, et al. Molecular identification of Coccidioides spp. in soil samples from Brazil. BMC Microbiol. 2011;11:108.

30. Baptista-rosas RC, Catalán-dibene J, Romero-olivares AL, Hinojosa A, Cavazos T, Riquelme M. Molecular detection of Coccidioides spp. from environmental samples in Baja California: linking Valley Fever to soil and climate conditions. Fungal Ecol. 2012;5(2):177-90.

31. Johnson SM, Carlson EL, Fisher FS, Pappagianis D. Demonstration of Coccidioides immitis and Coccidioides posadasii DNA in soil samples collected from Dinosaur National Monument, Utah. Med Mycol. 2014;52(6):610-7.

32. Teixeira MM, Barker BM. Use of population genetics to assess the ecology, evolution, and population structure of Coccidioides. Emerg Infect Dis. 2016;22(6):1022-30. 